Review of Income and Wealth 2013

DOI: $10.1111 /$ roiw.12051

\title{
INEQUALITY IN VIETNAMESE URBAN-RURAL LIVING STANDARDS, 1993-2006
}

\author{
By HuOng Thu LE*
}

Griffith University, Australia; and National Economics University, Vietnam

AND

\section{Alison L. BoOTh}

Australian National University, Australia; and University of Essex, U.K.

\begin{abstract}
We investigate urban-rural inequality in Vietnam using data from the Vietnam Living Standard Surveys between 1993 and 2006. We find that mean per capita expenditure of urban households is consistently twice as much as that of rural households and that the urban-rural gap monotonically increases from the poorer to the richer groups of the expenditure distribution. To isolate factors contributing to the urban-rural gap, we apply the Oaxaca-Blinder type decomposition to a newly developed unconditional quantile regression method. Factors contributing significantly to the high urban-rural gap include inter-group differences in education, household age structure, labor market activity, geographic location and their related returns, with education playing the most important role. Over the period, consistent with the country's massive rural-urban migration, we find that domestic remittance plays a significant role in shortening the urban-rural expenditure gap in the later years, 2002 and 2006 .
\end{abstract}

JEL Codes: C13, D31, O18, O53, P21

Keywords: expenditure distribution, Oaxaca decomposition, unconditional quantile regression, urbanrural inequality, Vietnam

\section{INTRODUCTION}

Vietnam has experienced continuously high economic growth since the transition from a centrally planned economy to a market economy began in 1986. Over the period, Vietnam has had one of the fastest improvements in living standards and the greatest reduction in poverty in the world. ${ }^{1}$ However, this period of

Note: We thank the editor, Conchita D'Ambrosio and two anonymous referees for their useful suggestions. For helpful comments we also thank Bob Breunig, Nicole Fortin, Paul Glewwe, Tue Gorgens, Ben Jann, Thomas Lemieux, Andrew Leigh, Amy Liu, Brain McCaig, Ha Trong Nguyen, Mathias Sinning, and participants in the Micro Brown Bag Seminar and the Second Economic Workshop on Vietnam at the Research School of Economics, the Australian National University, the 6th Australasian Development Economics Workshop at the University of Western Sydney, the 2010 Pacific Conference for Development Economics at the University of Southern California, and the 7 th Midwest International Economic Development Conference at the University of Minnesota. Any errors are our own.

*Correspondence to: Huong Thu Le, The Key Centre for Ethics, Law, Justice and Governance, Mt Gravatt Campus, Griffith University, QLD 4122, Australia (huong.le@griffith.edu.au).

${ }^{1}$ The national poverty rate reduces from 75 percent in 1988 to 37 percent in 1998 and 14 percent in 2008 (Pincus and Sender, 2008; Rama, 2010). From one of the poorest countries in 1985, Vietnam becomes a middle income country in 2010 .

(C) 2013 International Association for Research in Income and Wealth 
transition and opening up of the economy has seen a widening of the gap between the rich and the poor, and between urban and rural areas (Mundle and Arkadie, 1997; Glewwe et al., 2002; Rama, 2008). Closing the urban-rural gap is now a top priority in the Vietnamese Government's development strategy. It is at the centre of public debates and in the press, and a major concern of ordinary Vietnamese people and international donors. Understanding the magnitude of the Vietnamese urban-rural inequality and establishing the contributing factors to this urbanrural gap is a primary goal of this paper.

Two earlier studies used data from the first two Vietnam Living Standard Surveys (VLSSs), undertaken in 1992/1993 and 1997/1998, to examine this issue. These papers, by Nguyen et al. (2007) and Fesselmeyer and Le (2010), found a significant increase in urban-rural inequality between 1993 and 1998, and showed that urban-rural inequality plays the most important role in explaining national inequality.

Our paper contributes to the literature in three important ways. First, the new method of unconditional quantile regression (Firpo et al., 2009) is applied to examine the determinants of expenditure along the distribution. The advantage of the unconditional quantile regression over the traditional conditional quantile regression of Koenker and Bassett (1978) is that its estimated coefficients are interpreted as the impact of changes in the distribution of explanatory variables on the quantiles of the unconditional distribution of the dependent variable. Therefore, we can isolate factors contributing to the urban-rural expenditure gap across the whole distribution by applying the Oaxaca decomposition method directly to the estimation results from the unconditional quantile regression, without having to do the many simulations necessary in the alternative method of quantile regression-based decomposition. This represents our second contribution to the literature.

Third, our study covers a 13-year period between 1993 and 2006, which is longer than previous studies on urban-rural living standard inequality in Vietnam covering only five years between 1993 and 1998. As noted above, this period is important for Vietnam not only because of its continuously high economic growth, but also because of significant changes in the structure of the economy and its accelerated integration into the world market. Vietnam resumed relations with the International Monetary Fund and the World Bank in 1992; established political normalization with the United States in 1995; became a member of the Association of Southeast Asian Nations (ASEAN) in 1995, ASEAN Free Trade Area in 1996, and Asia-Pacific Economic Cooperation in 1998; signed the Bilateral Trade Agreement with the U.S. in 2000; and joined World Trade Organization in January 2007. These have led to a marked change in distribution of outcome.

We find that, from 1993 to 2006, real per capita expenditure of the Vietnamese doubles. There is also a huge gap in expenditure between the urban and rural sectors. Mean per capita expenditure of urban households is consistently twice as much as that of rural households, and the urban-rural gap monotonically increases from the bottom to the top of the distribution. Our decomposition results show a number of factors contributing significantly to the high urban-rural gap. These include the inter-group differences in education, industrial structure, labor market activity, household demographic structure, geographic location, and their 
related returns. Of these, education plays the most important role. In line with the country's recent massive rural-urban migration, we find that, in the latter years of our observation period, the receipt of domestic remittances is associated with a significant increase in rural households' expenditure and a reduction in the urbanrural expenditure gap. The impact is highest at the lower end. Adjusting the average characteristics of rural households to those of urban households reduces about 50 percent of the urban-rural expenditure gap.

The remainder of the paper is set out as follows. Section 2 summarizes Vietnam's transition and urban development. Section 3 describes the data. An overall picture of urban-rural inequality from both descriptive statistics and inequality indices analyses is provided in Section 4, followed in Section 5 by exposition of the Firpo et al. (2009) method of unconditional quantile regression. Our applications to it of the Oaxaca-Blinder decomposition are presented in Section 6. The conclusions and policy implications are given in the final section.

\section{Background of the Vietnamese Transition and Urban Development}

Vietnam is an excellent country in which to base a study of the urban-rural inequality. In 2008, Vietnam has 28 percent of the total population living in urban areas (General Statistics Office of Vietnam, 2009). The low rate of urban population in Vietnam reflects the lack of urban development in the country. ${ }^{2}$ As with many countries in the region, Vietnam was an agricultural economy prior to 1945, with over 90 percent of the population living in rural areas, where rice was the major crop of cultivation. Vietnam experienced long lasting periods of the wars in the twentieth century. After the war ended, Vietnam was a centrally command and control economy. During this period, the urban population was kept stable at around 19 percent. By the end of the centrally planned period, Vietnam was one of the poorest countries in the world.

Since the transition away from the centrally planned toward a marketoriented economy started in 1986, Vietnam has experienced continuously high economic growth and a high rate of urbanization. ${ }^{3}$ However, there is unbalanced growth between urban and rural areas. While the urban areas of Vietnam contain only 25 percent of the population, they account for up to 70 percent of national economic growth (World Bank, 2004). This unbalanced growth creates a marked unevenness between urban and rural areas in terms of employment opportunities and living standard improvements (Phan and Coxhead, 2010). Therefore, even though the overall standard of living improved remarkably over the last two decades, poverty remains widespread and is overwhelmingly found in rural areas. For example, in 2004, 25 percent of rural people lived in poverty as compared with an urban poverty rate of 3.6 percent (Vietnamese Academy of Social Science, 2007). Recent studies about overall inequality in Vietnam - by the Asian Development Bank (2007) using per capita expenditure and McCaig et al. (2009)

\footnotetext{
${ }^{2}$ The percentage of East Asian population that is urban is 45 percent, as compared with 48 percent for the entire world (United Nations, 2008a).

${ }^{3}$ The proportion of population living in urban areas in Vietnam increases from 19 percent in 1986 to 28 percent in 2008 (United Nations, 2008a).
} 
using per capita income - emphasize that this urban-rural inequality has been the most important contributing factor to national inequality.

\section{DAta AND SAmple}

We use data from five waves of the Vietnam Household Living Standard Surveys. The first two waves are called the Vietnam Living Standard Surveys (VLSSs) undertaken in 1992/1993 and 1997/1998, while the next three waves are called the Vietnam Household Living Standard Surveys (VHLSSs) undertaken in 2002, 2004, and 2006. These are nationally representative surveys conducted by Vietnam's General Statistics Office with technical assistance from the World Bank. In the VLSS 1992/1993, the overall sampling frame was first stratified into urban and rural areas, with proportions of the sample in each based on the 1989 census being 20 and 80 percent, respectively (World Bank, 2001). Then within the urban and rural areas, a list of communes was selected to ensure that they are spread evenly among all provinces of Vietnam. The sample of the first VLSS - VLSS 1992/1993 - is self-weighted, which means each surveyed household has the same probability of being selected. In subsequent waves, due to over sampling in certain areas, a sample weight is attached to each surveyed household. Different from the initial VLSS, the first sampling unit of VHLSSs is at the provincial level. Then within each province, further stratification is done by urban and rural areas to ensure a high level of precision for the urban and rural estimates.

Although the subsequent VHLSS questionnaires were simplified compared to the first two waves of VLSS, the question design in both follows the standard set for the Living Standard Measurement Surveys of the World Bank. As a result, these surveys contain comprehensive and comparable information across years, in terms of both household characteristics and household expenditure items, thus facilitating welfare analysis at a household level.

There are 4000 households surveyed in VLSS 1993 who were re-interviewed in 1998. There are also panel samples from the last three waves-VHLSS 2002, 2004, and 2006. However, there are no households re-interviewed between the VLSS and the VHLSS. For our purpose of observing the whole period and making our observed sample nationally representative, we analyze all five waves in separate cross-sections. The last column of Table 1 indicates the sample size separately, by urban and rural categories. Column 2 reports the percentage of urban households in the sample, adjusted by household weights. These numbers approximate the actual percentage of registered urban population. ${ }^{4}$

To compare the difference between urban and rural living standards, we use household real per capita yearly expenditure (RPCEXP). The calculation of expenditure follows the scientific formula used in the Living Standard Measurement Survey of the World Bank. Specifically, household total expenditure is calculated as the sum of expenditure on food and non-food items. Food expenditure includes expenditure on both purchased items and home-produced products. The value of consumption from home-produced products is calculated by using

\footnotetext{
${ }^{4}$ The survey samples only cover the registered residence. Given that unregistered migrants account for a significant part of the "floating" urban population, our results must be interpreted with caution.
} 
the total quantity consumed multiplied by the unit value of such consumption if it was purchased in the market. Non-food expenditure includes expenditures on daily items, utilities, transportation, entertainment, education, health, the imputed values of household appliances or other consumer durables to be consumed in the year, house rent or, for those who live in their own house, the imputed depreciation value of the house in the year. Expenditures on consumer durables, house building, social funds, and the purchase of gold, silver, precious gems, stocks, or bonds are excluded (World Bank, 1998a, 1998b, 2001; General Statistics Office of Vietnam, 2006). Thus the expenditure calculated from the survey is relatively good for living standard measurement. Current expenditure at the time of the survey is adjusted for spatial and temporal price indexes and then converted to the values of January 2006. Per capita expenditure is calculated by dividing total household expenditure by the household size.

\section{Urban-Rural INEQUALity in Vietnam, 1993-2006}

\section{Urban-Rural Expenditure Gap: Magnitude and Trends}

Table 1 presents per capita expenditure figures at the mean and at selected percentiles by urban and rural households, and shows that expenditure is consistently higher in urban than rural areas. The urban-rural expenditure ratio at the mean increased from 1.91 in 1993 to 2.36 in 2002, before declining to 2.24 in 2004 and 2.01 in 2006.

Table 1 also shows that the expenditure of the top decile of urban households is four to five times higher than the expenditure of the bottom decile. It is seven to nine times higher than the expenditure of the bottom decile of rural households. Moreover, the value of the top decile of rural expenditure is only about the median urban expenditure. These figures confirm a long lasting Vietnamese saying, "Giau nha que khong bang keo le thanh thi," meaning that the rural rich are not as wealthy as the urban poor who work in the city street.

Further illustration of the expenditure distribution of the urban and rural sectors is presented in Appendix A. It can be seen that the urban distribution is more dispersed while the rural distribution is more concentrated, confirming that there is higher inequality within urban than rural sectors. In addition, the urban density lies to the right of the rural one, showing that urban expenditure is consistently higher than the rural counterpart.

Figure 1 illustrates the evolution of the urban-rural natural log RPCEXP gap along the distribution. An important deduction from the figure is that the urbanrural gap is monotonically increasing from the poorer to the richer groups of the expenditure distribution. From 1993 to 1998, the gap increased at all points in the distribution. From 1998 to 2002, the gap continued to increase in the middle of the distribution but decreased slightly in the two tails. Over the whole period, the urban-rural expenditure gap at the mean peaked in 2002, then decreased. While the decrease in the urban-rural expenditure gap at the mean from 2002 to 2004 mostly came from the decrease of the gap in the upper half of the expenditure distribution, the decrease in the urban-rural expenditure gap at the mean from 2004 to 2006 came from the decrease of the gap at all points in the distribution. 


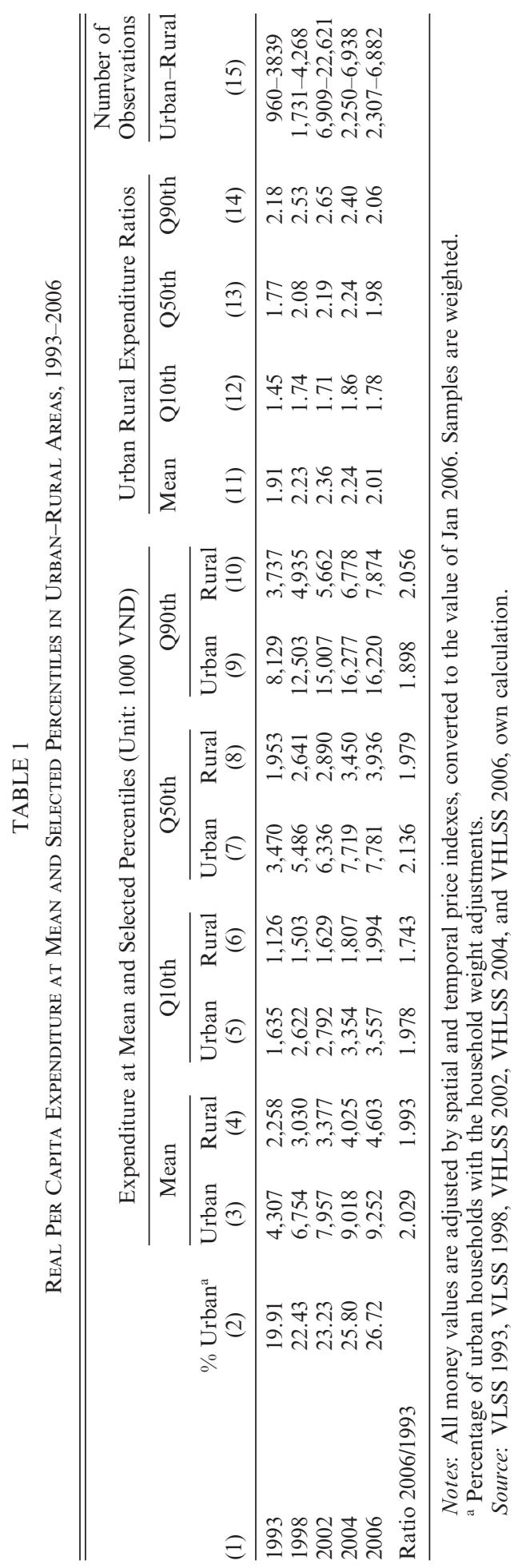

(C) 2013 International Association for Research in Income and Wealth 


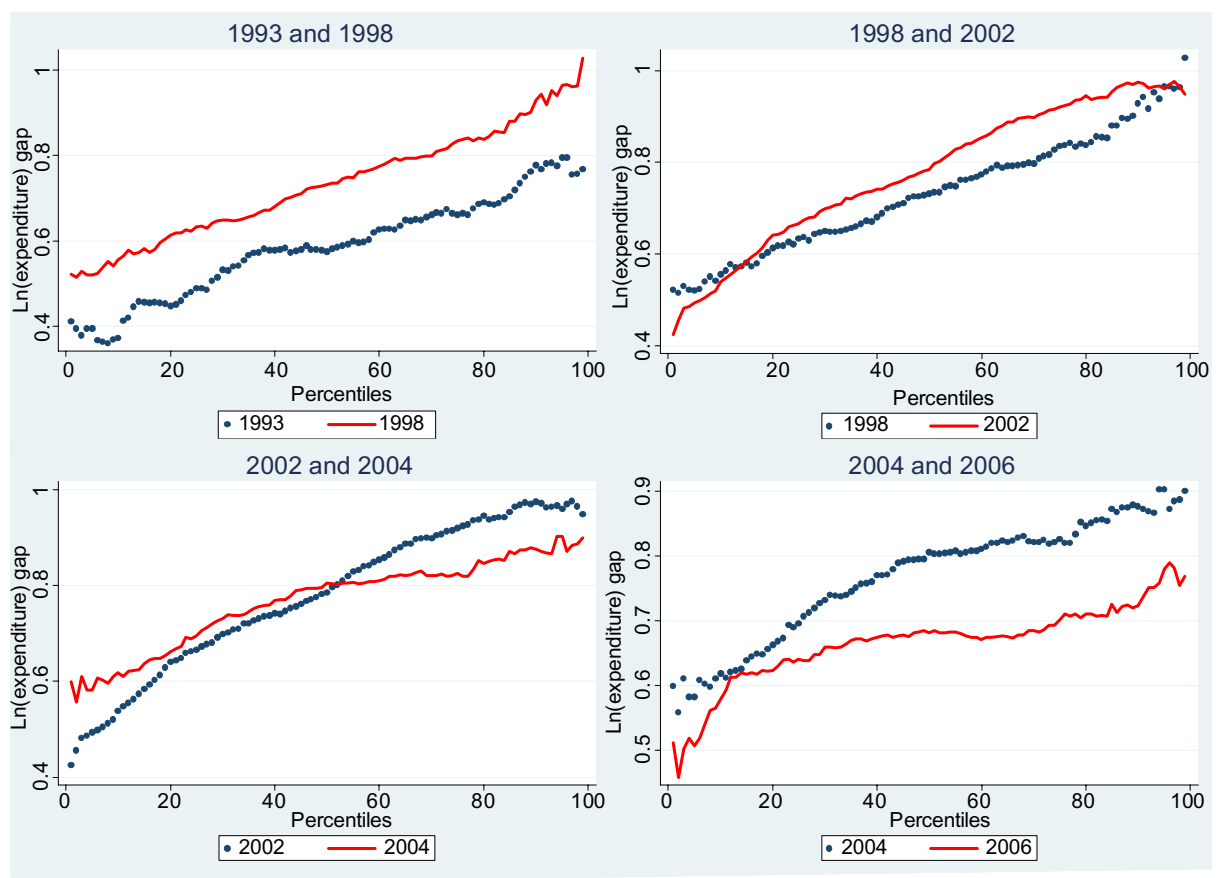

Figure 1. Expenditure Gap between Urban and Rural Areas across Percentiles, 1993-2006

Notes: All values are adjusted by spatial and temporal price indexes, converted to January 2006 values. Samples are weighted.

Source: VLSS 1993, VLSS 1998, VHLSS 2002, VHLSS 2004, and VHLSS 2006, own calculations.

\section{Urban-Rural Inequality from Inequality Indices Analysis}

We next use inequality indices to investigate inequality of the whole nation as well as by urban-rural sectors. Specifically, we identify to what extent the between group inequality by urban-rural contributes to the national inequality during the 1993 to 2006 period. We also briefly compare urban-rural inequality in Vietnam with other countries at the same level of development and with those at a similar stage of transition.

Table 2 reports inequality indices across years for the whole nation as well as by urban-rural sectors. Using the Gini index, it can be seen that national inequality increased in the initial period of reform (from 1993 to 2002), remained unchanged (from 2002 to 2004), and then decreased.

How does this compare with other countries with a comparable level of GDP per capita? Inequality in Vietnam in 2004 is 0.37 , which is lower than that of Cambodia (whose Gini was 0.42 in 2004), is equal to that of India, and is a little bit higher than that of Indonesia (whose Gini was 0.34 in 2002). What about other countries at a comparable transition pattern? While Vietnam has the same pattern of economic transition as China, and is similar to some extent to Russia and 
TABLE 2

INEQUALITy IndeXes In Urban-RuRAL Areas, 1993-2006

\begin{tabular}{lccccccc}
\hline \hline & \multicolumn{3}{c}{ Gini } & & \multicolumn{3}{c}{ Theil } \\
\cline { 2 - 3 } \cline { 7 - 8 } & All & Urban & Rural & & All & Urban & Rural \\
\hline 1993 & 0.33 & 0.34 & 0.28 & & 0.20 & 0.19 & 0.14 \\
1998 & 0.35 & 0.34 & 0.27 & & 0.23 & 0.20 & 0.13 \\
2002 & 0.37 & 0.35 & 0.28 & & 0.25 & 0.21 & 0.14 \\
2004 & 0.37 & 0.33 & 0.29 & & 0.24 & 0.18 & 0.15 \\
2006 & 0.36 & 0.33 & 0.30 & & 0.23 & 0.19 & 0.16 \\
\hline
\end{tabular}

Notes: Samples are weighted.

Inequality indexes are calculated with 500 bootstrap replications. All values are significant at $1 \%$ level.

Source: VLSS 1993, VLSS 1998, VHLSS 2002, VHLSS 2004, and VHLSS 2006, own calculation.

Poland, the Gini index of Vietnam in 2004 is lower (Appendix B). ${ }^{5}$ However, we cannot draw any precise conclusions about the comparative inequality levels between Vietnam and these last countries because each has different level of development as measured by per capita GDP. Positively, the trend of overall inequality in Vietnam in recent years has reduced despite the country's continuously high economic growth.

In all years, inequality is higher in the urban than the rural sector and inequality of the whole nation is higher than inequality in urban or rural sectors alone. We further carry out the Theil inequality index's decomposition into the contributions of between- and within-group inequality across different characteristics of the household. The decomposition results are presented in Appendices $\mathrm{C} 1$, $\mathrm{C} 2$, and $\mathrm{C} 3$, and show that the urban-rural between-group inequality makes the largest contribution to the national inequality. Specifically, the between-group urban-rural inequality accounted for 21 percent of the overall inequality in 1993; this increased rapidly to 31 percent in 1998, 33 percent in 2002, and then fell slightly to 31 percent in 2004 and decreased to 25 percent in 2006 .

Compared with some other countries in the Asian region, such as India, Indonesia, and the Philippines, Vietnam has higher urban-rural inequality. Compared with China, Vietnam has lower urban-rural inequality and less increase in urban-rural inequality during the economic transition process. ${ }^{6}$

There are several possible reasons for why the per capita expenditure of households in the rural sector is lower than that of households in the urban sector. Among them are inter-group differences in education, demographic structure, labor market activity, geographic location, and the like. For example, people of urban households have more years of schooling than those of rural households, and living standards are positively associated with the years of schooling. Furthermore, urban households have more favorable demographic characteristics. These

${ }^{5}$ Grün and Klasen (2001) provide a comprehensive investigation of inequality in transition countries in Eastern Europe and the former Soviet Union during their transitional period.

${ }^{6}$ Urban-rural expenditure inequality in China contributed 27 percent to the national inequality in 1985, 40 percent in 1995, and 44 percent in 2004 (Asian Development Bank, 2007). See Sicular et al. (2007) for an investigation of China's urban-rural income inequality. 
include a smaller household size, a larger proportion of laborers, and a smaller proportion of children. Urban households are more engaged in services and the manufacturing sector where returns are higher, while rural households are more engaged in the agricultural sector where returns are relatively low. Urban households receive more foreign remittances. Urban households are located in areas with more favorable geographic and infrastructure conditions.

To what extent are expenditures determined by these observed productivity related characteristics in urban and rural regions? How much of the urbanrural expenditure differential is due to the differences in average characteristics? How much of the expenditure differential is due to difference in returns and other factors not captured in the model? The regressions and decompositions of the next sections will answer these questions.

\section{Determinants of Expenditure in Urban and Rural Sectors}

\section{Estimation Methods}

Our particular interest here is to relate the household's productivitydetermining characteristics to its level of per capita expenditure. Because in both urban and rural sectors the mean expenditure is always higher than the median, the expenditure distribution is right skewed, and it contains extreme values. This characteristic suggests the need for investigating the determinants of expenditure not only at the mean but along the entire distribution. The quantile regression approach is particularly useful for our purpose.

While the (conditional) quantile regression method, as introduced by Koenker and Bassett (1978), allows us to investigate the effect of an explanatory variable on the entire distribution of the outcome, the method is restrictive in that a change in the distribution of covariates may change the interpretation of the estimated coefficients (Firpo et al., 2009; Powell, 2011). Therefore, in the absence of the rank-preserving condition, the estimated coefficients from the (conditional) quantile regression are not explained as the impacts of a change in explanatory variables on the outcome of interest for those at a specific point of the distribution.

The new unconditional quantile regression method developed by Firpo et al. (2009) overcomes this restriction. The method estimates the impact of changes in the distribution of explanatory variables on the unconditional marginal distribution of the outcome variable. Technically, the unconditional quantile regression method runs a regression of the estimated re-centered influence function $(R I F)$ on a set of explanatory variables.

The RIF, introduced by Firpo et al. (2009), is the sum of the value function and the influence function. The influence function is the first derivative of an estimator; it measures a magnitude of a change of the distribution if we add an additional observation (Hampel, 1974). For example, let $T$ be the value function and $F$ be the probability for which $T$ is defined. Then a slight perturbation of $F$ by a point mass at $y$ is the mixture model from which an observation has probability $(1-\varepsilon)$ of being generated by $F$ and probability $(\varepsilon)$ of being an arbitrary value $\delta_{y}$; it is written as: 


$$
F_{\varepsilon}(y)=(1-\varepsilon) \cdot F+\varepsilon \cdot \delta_{y}
$$

The influence function of an estimator $T$ with probability distribution $F$ at point $y$ is:

(2)

$$
I F(y, T(F))=\lim _{\varepsilon \rightarrow 0} \frac{\left\{T\left[F_{\varepsilon}(y)\right]-T[F(y)]\right\}}{\varepsilon}=\lim _{\varepsilon \rightarrow 0} \frac{\left\{T\left[(1-\varepsilon) \cdot F+\varepsilon \cdot \delta_{y}\right]-T(F)\right\}}{\varepsilon} .
$$

Given the influence function, the re-centered influence function of an estimator $T$ with probability distribution $F$ at point $y$ is:

$$
R I F(y, T(F))=T(F)+I F(y, T(F)) .
$$

Because the expected value of the influence functions equals zero:

$$
\int_{-\infty}^{+\infty} I F(y, T(F)) d F(y)=0,
$$

the expected value of the re-centered influence functions is the exactly the value function:

$$
\int_{-\infty}^{+\infty} R I F(y, T(F)) d F(y)=\int_{-\infty}^{+\infty}[T(F)+I F(y, T(F))] d F(y)=T(F) .
$$

Therefore, the law of iterated expectations applied to the conditional mean:

$$
E_{x}[f(y \mid x)]=\int_{-\infty}^{+\infty} f(y \mid x) f(x) d x=f(y),
$$

can also be applied to the RIF:

$$
E_{x}[R I F(y \mid x)]=T(F(y)) .
$$

This important characteristic allows the estimated coefficient from the unconditional quantile regression using $R I F$ to be explained similarly to the estimated coefficient from the ordinary least squares regression (OLS) but applied to any statistics of interest (Firpo et al., 2009).

If our statistics of interest is the $\tau^{\text {th }}$ quantile, the $R I F$ at a given $q_{\tau}$ is:

$$
\operatorname{RIF}\left(Y ; q_{\tau}\right)=q_{\tau}+\operatorname{IF}\left(Y ; q_{\tau}\right)=q_{\tau}+\frac{\tau-1\left\{Y \leq q_{\tau}\right\}}{f_{Y}\left(q_{\tau}\right)},
$$

where $1\left\{Y \leq q_{\tau}\right\}$ indicates the dummy variable for whether the value of $Y$ is below $q_{\tau} ; f_{Y}\left(q_{\tau}\right)$ is the probability density of $Y$ associated with the probability distribution $F$ evaluated at $q_{\tau}$. An estimation of $R I F$ at a given $\tau^{\text {th }}$ quantile involves two components. The first component, $\hat{q}_{\tau}$ - the $\tau^{\text {th }}$ sample quantile-is estimated as in Koenker and Bassett (1978):

$$
\hat{q}_{\tau}=\operatorname{argmin}_{q} \sum_{i=1}^{N}\left(\tau-1\left\{\left(Y_{i}-q\right) \leq 0\right\} \cdot\left(Y_{i}-q\right)\right) .
$$


The second component, $\hat{f}_{Y}\left(\hat{q}_{\tau}\right)$ - the density estimator of $Y$ at point $\hat{q}_{\tau}$-is estimated using the kernel density: $\widehat{f}_{Y}\left(\hat{q}_{\tau}\right)=\frac{1}{N \cdot b} \cdot \sum_{i=1}^{N} K_{Y}\left(\frac{Y_{i}-\hat{q}_{\tau}}{b}\right)$, where $K_{Y}(z)$ is the Gaussian kernel and $b$ is the bandwidth.?

The Firpo et al. (2009) new method of unconditional quantile regression can be done through one of three estimation techniques: OLS (called RIF-OLS), logistic (called RIF-logit), or non-parametric (called RIF-nonparametric). ${ }^{8}$ For simplicity, in this application we use the RIF-OLS. Consistent estimates of this method are obtained under the assumption that: $\operatorname{Pr}\left\{Y>q_{\tau} \mid X=x\right]$ is linear in $x$. The estimation of RIF-OLS is similar to OLS:

$$
\widehat{\beta_{\tau}}=\left(X^{\prime} X\right)^{-1} X^{\prime} \widehat{R I F}\left(Y, \hat{q}_{\tau}\right) .
$$

The only difference is the replacement of the estimated values of $R I F$ at a given quantile as a new dependent variable. If our statistic of interest is the mean, then the estimation of RIF-OLS for the mean becomes exactly OLS.

\section{Model Specifications and Estimation Results}

Using OLS and unconditional quantile regression, we investigate how the relationship between the natural log of real per capita yearly expenditure (RPCEXP) and a set of explanatory variables differs between urban and rural sectors at the mean and at various quantiles of the expenditure distribution. We estimate an expenditure equation of the form:

$$
Y_{i}=\alpha+\beta X_{i}+\gamma U_{i}+\delta U_{i} \cdot X_{i}+\varepsilon_{i},
$$

where $Y_{i}$ is the natural log of RPCEXP of household $i, U_{i}$ is the urban dummy, $X_{i}$ is the vector of explanatory variables for household $i$, and $U_{i} \cdot X_{i}$ is the interaction between the urban dummy and the explanatory variables. The vector of coefficients $\beta$ is the returns to characteristics, and $\gamma$ and $\delta$ give the intercept and slope differential associated with urban location.

The set of explanatory variable $X_{i}$ includes education, demographic, employment, and geographical characteristics of the household. In particular, we use characteristics of the most educated working age person in the household, including his or her years of schooling, gender, ethnicity, marital status, experience, working status, industry of working, and sector of working as explanatory variables. ${ }^{9}$ For households with no working age individual, we use the years of

${ }^{7}$ Other methods of density estimation can be applied.

${ }^{8}$ Firpo et al. (2009) show that three estimation techniques give similar estimation results. Some other applications of the Firpo et al. (2009) unconditional quantile regression method are Chi and $\mathrm{Li}$ (2008), Kassenböhmer and Sinning (2010), and Sakellariou (2011).

${ }^{9}$ We first carry out three different estimations using: characteristics of the household head, characteristics of the most educated household head or spouse, and then characteristics of the most educated working age person in the household. The estimation results suggest that the fit of the model (R-square) is usually highest when using characteristics of the most educated working age person in the household. We then use characteristics of the most educated working age person in the household as explanatory variables in both regression and decompositions. 
schooling of the more educated household head or spouse and his or her attributes. Household demographic variables include household size and the household proportions of children, laborers, and the elderly. ${ }^{10}$ We evaluate the impact of remittances from foreign and domestic sources on household expenditure separately. Finally, we include six dummies to control for seven regional differences - this is more detailed than the two regions (North-South) studied in Nguyen et al. (2007). The reason for doing this comes from our results of the Theil decomposition by North-South and by seven regions. The between North-South difference contributes a modest percentage to the overall inequality of around 3-8 percent across the years 1993-2006, compared to the between seven regions difference, which is around 12-18 percent across the years 1993-2006, as shown in Appendix C1. So our results will be more accurate at regional levels. Moreover, the inclusion of the six regional dummies allows us to capture part of the geographic differences in price which, it is held, do not fully capture regional price differences in the VHLSSs for 2002 and 2004 (McCaig et al., 2009).

To begin with, we estimate a restricted version of equation (11) that includes only the intercept, the urban dummy, and a set of all explanatory variables at the mean using OLS and at selected quantiles using the unconditional quantile regression. The estimation results suggest that all the urban dummies have positive coefficients and are highly statistically significant implying that, other things equal, an urban household has higher per capita expenditure than a comparable rural household. Interestingly, the coefficients of the urban dummies increase monotonically from the bottom to the top of the distribution, implying that controlling for other characteristics the urban-rural gap is higher among those with higher expenditures. This is true for all years.

Next, we estimate a full specification of equation (11) _ including the intercept, the urban dummy, and the set of explanatory variables, plus the interaction terms of the urban dummy with the set of explanatory variables - at the mean using OLS and at various quantiles using unconditional quantile regression. We carry out an $\mathrm{F}$ test for the hypothesis that all the coefficients of urban interaction terms are equal to zero. The test results reject the null hypothesis, suggesting that there are indeed significant differences in the return to characteristics between the urban and rural sectors.

We then use the OLS and the unconditional quantile regression to estimate the determinants of expenditure at the mean and at selected quantiles for the urban and rural sectors separately. For parsimony, only the estimation results for 1993, 2002, and 2006 are reported in Tables 3 and 4.

The values of $\mathrm{R}^{2}$ from the regression results imply that the fit of the model is higher at the mean and at the middle of the distribution than at the two tails.

\footnotetext{
${ }^{10}$ In Vietnam, at the age of 15 children finish lower secondary school, and then many of them work, especially in rural areas. Article 6 of the Vietnamese Labor Code (1994) regulates that employees are people at least 15 years old who are able to work and have entered into a labor contract (The National Assembly, 1994). So we identify laborers as those who are over 15 to retirement age, currently not at school, and working. Old people are those who are over the retirement age (currently 60 years for males and 55 years for females).
} 


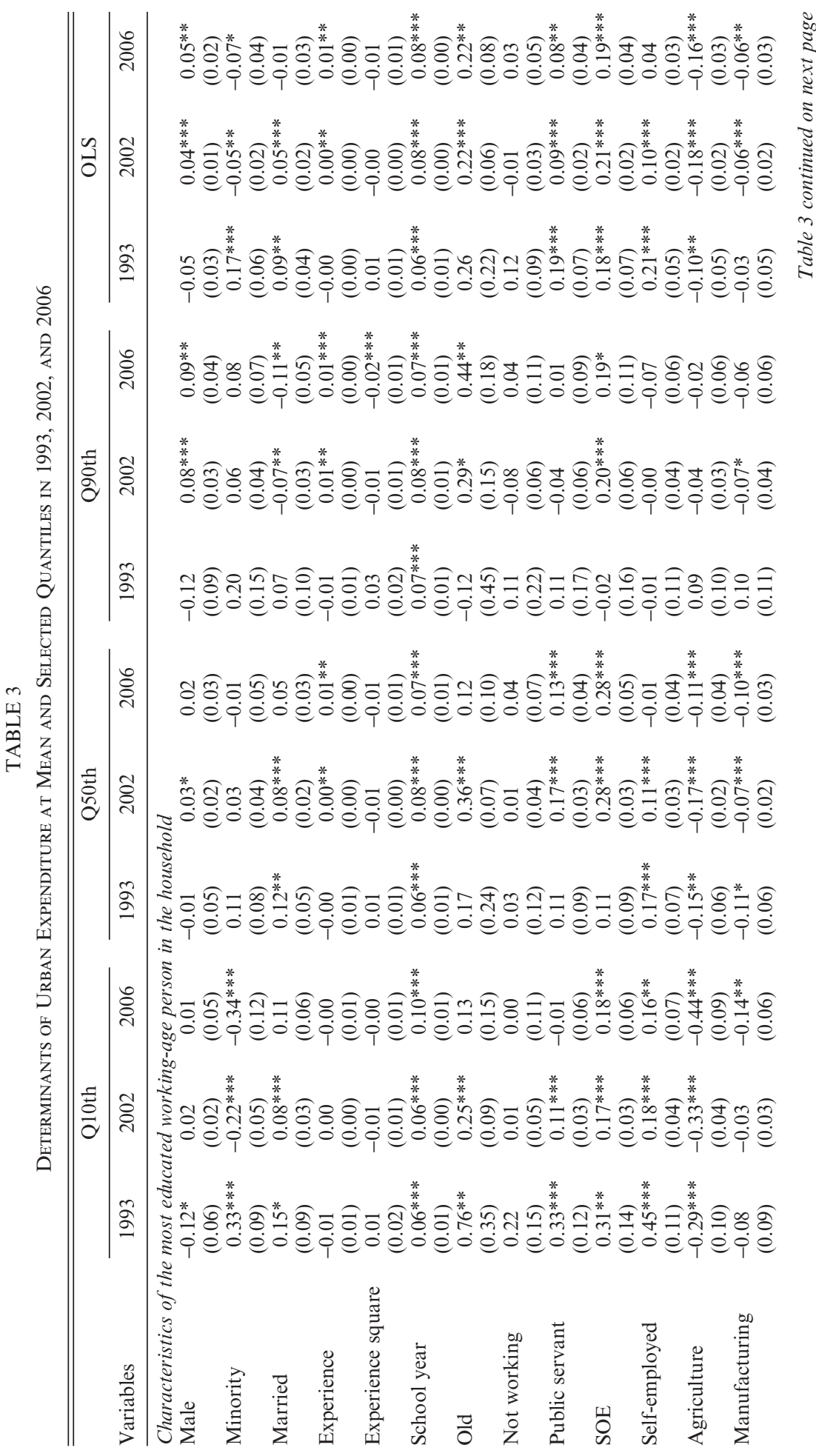




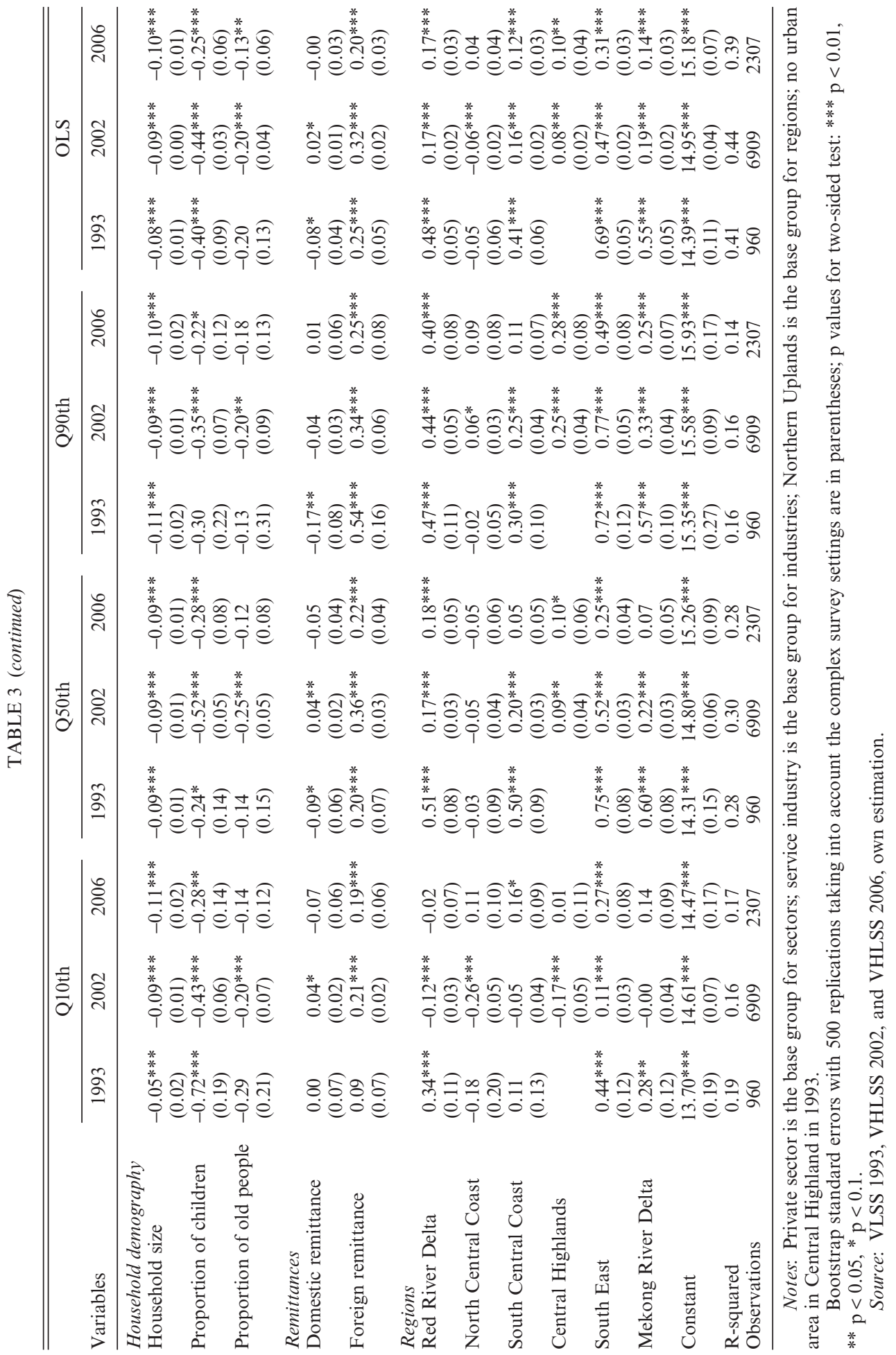




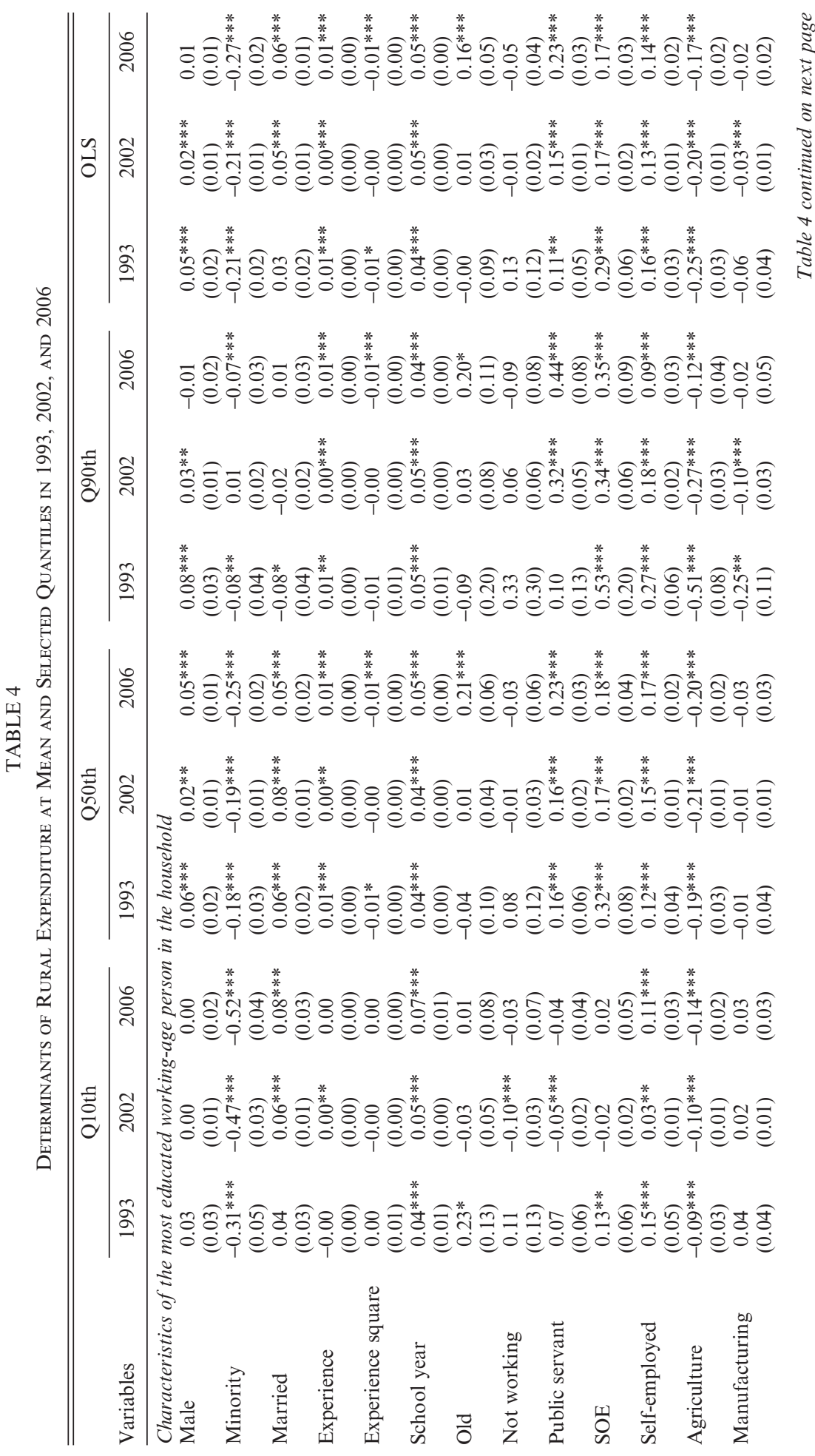




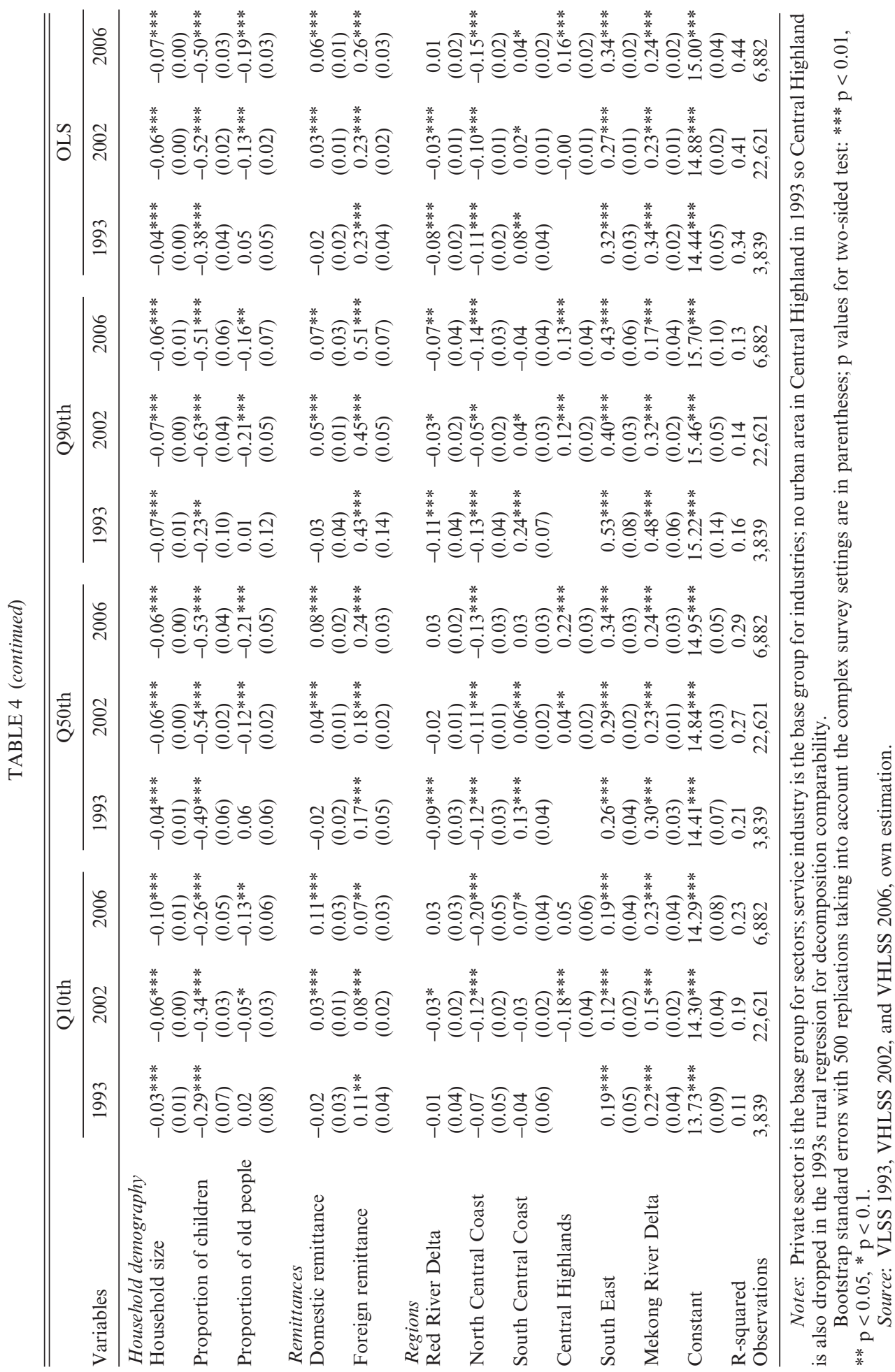


We now turn to a discussion of the impact of the variables included in the regression. First, education of the most educated working age person in the household is highly statistically significant and positively related to household per capita expenditure in both urban and rural sectors, across all quantiles and in all years. For example, in 1993, other things being equal, at the mean, one additional year of education of the most educated working age person in the household increased household per capita expenditure by 6 percent in the urban sector and 4 percent in the rural sector. By 2006, at the mean and at all points along the expenditure distribution, return to education of the urban sector is consistently about 3 percent higher than that of the rural sector. The sizable urban-rural gap in return to education observed in Vietnam is similar to the phenomenon observed in other developing countries (Ravallion and Wodon, 1999). Notably, in the initial period of reform, between 1993 and 2002, there was a large increase in return to education for the middle and upper class in the urban sector. However, in the latter period, in both urban and rural sectors, return to education is high for the poor, suggesting that education is an effective channel for inequality reduction.

Second, consider ethnicity. In the rural sector, other things being equal, ethnic households have significantly lower expenditure than the majority. The expenditure differential by ethnicity is highest at the lower end. In the urban sector, there is no expenditure differential by ethnicity in 1993; however, by 2006 these ethnic households have lower expenditure than the majority. This is true at almost all points along the urban expenditure distribution.

Third, consider the effect of household demographics. Household size and the age structure of household members are both highly statistically significant in determining household expenditure. The negative coefficients imply that larger households, or those with more children, have lower per capita expenditure. Households with more elderly also have lower expenditure and the negative relationship is particularly significant for the rural sector.

Fourth, consider industries. In all years, households with the most educated people working in the agricultural industry are those with the lowest expenditure. Over the studied period, although in the upper part of the rural expenditure distribution the return to working in agriculture improves significantly, in the lower part, the return to working in agriculture remains stable.

Fifth, consider sectors. Households with the most educated person working in the private sector consistently have lower expenditure than comparable households with the most educated person working in the state-owned enterprises (SOE) or as a public servant. In 1993, the initial stage of our observed period, ceteris paribus, households with a self-employed head working in the informal sector in urban areas had higher expenditure than did households where the head worked in the formal private sector. However, by 2006, households with a self-employed head now have lower expenditure compared to households with the head working in the private sector. This is consistent with the fact that, during the initial period of economic transition with the contraction of the state sector, the informal sector developed quickly to take the advantage of new market opportunities which previously had been restrained during the long period of centrally planned. However, as the country continued its transition, the labor market became increasingly formalized. There is not only a decline in 
return of the informal sector, but also a contraction in the share of the informal sector in the economy. ${ }^{11}$

Sixth, consider remittances. The receipt of foreign remittances significantly improves household expenditure in both urban and rural areas and in all years. A household with foreign remittance on average has 24 percent higher per capita expenditure than their counterparts and the positive impact of foreign remittance on improving rural household's expenditure increases from the lower to the upper end. An explanation for the phenomenon may come from the fact that, in order for a person in the family to migrate - to work in a foreign country in the kind of labor exportation - the family has to pay an initial cost. The cost is for language and skill acquisition, travelling, and setting up. For poor families, this initial cost is often covered by borrowing. When receiving foreign remittances, the poor families have to pay the borrowed money back first before they can use remittance to increase their expenditure. As a result, a rich household is likely to have a larger increase in their expenditure when receiving foreign remittances than poor households.

The impact is different for the receipt of a domestic remittance. In 1993, only 17 percent of rural households received domestic remittance and domestic remittance was not significant in improving rural household's expenditure. However, the country's recent massive rural-urban migration results in a large increase in proportion of rural households receiving domestic remittance. The rate is 76 percent in 2002 and up to 87 percent in 2006. By 2006, on average, rural households with domestic remittance have 6 percent higher per capita expenditure than their counterparts. The positive impact of domestic remittance on improving rural household's expenditure is highly significant at all points along the distribution and highest for poor households at the lower end. For example, at the 10th quantile, rural households with domestic remittance have up to 11 percent higher per capita expenditure than their counterparts.

Finally, consider regions. Other things equal, the urban living standard is highest in the Southeast, followed by the Red River Delta. This is consistent with the fact that the urban Southeast is the largest urban economic center of Vietnam, containing the biggest city-Ho Chi Minh City. The urban Red River Delta is the political center and the second biggest economic center of Vietnam, where the capital Hanoi is located. While living standards in urban areas are closely related to the concentration of economic and political activities, living standards in rural areas are closely related to agricultural productivity. Rural households in the South have remarkably higher living standards than rural households in the North. This is consistent with the fact that agricultural production in the South is easier, with more fertile land, more favorable weather conditions, and a larger scale of production. Among rural areas, the rural North Central Coast has the lowest living standard. In addition, the gap in rural living standards of the two poorest regions, the North Central Coast and the Northern Uplands, is highest at the lower end. This suggests that poor rural households living in the North Central Coast should be of special attention in the governmental poverty reduction programs.

${ }^{11}$ The proportion of laborers receiving wages increased from 16 percent in 1993 to 30 percent in 2002, and 33 percent in 2006. 


\section{Factors Contributing to the Urban-Rural Expenditure Gap}

\section{Decomposition Method}

In this section, we examine the factors contributing to the urban-rural expenditure gap at the mean and at selected quantiles. We do so by using a variation of the Oaxaca-Blinder decomposition (Blinder, 1973; Oaxaca 1973) of the form:

$$
\hat{Y}_{u}-\hat{Y}_{r}=\underbrace{\left(\hat{X}_{u}-\hat{X}_{r}\right) \hat{\beta}^{*}}_{\text {"Explained" }}+\{\underbrace{\hat{X}_{u}\left(\hat{\beta}_{u}-\hat{\beta}^{*}\right)+\hat{X}_{r}\left(\hat{\beta}^{*}-\hat{\beta}_{r}\right)}_{\text {"Unexplained" }}\} \text {, }
$$

where $Y$ is the natural $\log$ of real per capita household expenditure; $\bar{X}$ is a vector of the mean observed characteristics; $\hat{\beta}$ is a vector of the estimated coefficient in the regression model of log RPCEXP on a set of explanatory variables, including the constant; and $\hat{\beta}^{*}$ is a vector of the estimated coefficients from the pooled urban and rural sample with other explanatory variables and the urban dummy. ${ }^{12}$

The first term on the right-hand side is the part of the inter-group difference due to different observed productivity-related characteristics - the "explained part." The second term on the right-hand side is the difference in factors other than the observed characteristics - the "unexplained part," sometimes interpreted as discrimination.

In the presence of categorical variables, the results of a detailed decomposition will be sensitive to the choice of the reference group. Some solutions are proposed to solve the problem by imposing additional restrictions to transform the estimated coefficients. However, doing so will lose the simple meaningful interpretations and preclude comparisons across years (Fortin et al., 2011). To facilitate the interpretation and ensure compatibility, we perform all decompositions with the same reference groups.

\section{Decomposition Results of Factors Contributing to the Urban-Rural Expenditure Gap}

Table 5 reports the urban-rural per capita expenditure gap, together with its contributing factors at the mean and selected quantiles in 1993, 2002, and 2006.

In all years, the urban-rural expenditure gap comes from both the inter-group difference in average characteristics and their related returns. The inter-group differences in characteristics explain about a half of the overall urban-rural expenditure gap.

Regarding the contributions of explanatory variables, education plays the most important role. The higher education of urban households and the higher

\footnotetext{
${ }^{12}$ The reason for including the urban dummy as a group indicator in estimating the reference structure is discussed in Fortin (2008) and Jann (2008). An example is that, if the average education of urban households is higher than that of rural ones, then the estimated coefficient of return to education of the pooled sample without urban dummy will capture a part of the mean difference in education between the two groups, resulting in the estimated return to education of the pooled sample being higher than the estimated return to education of urban or rural households alone. This phenomenon will understate the unexplained part and overstate the explained part.
} 


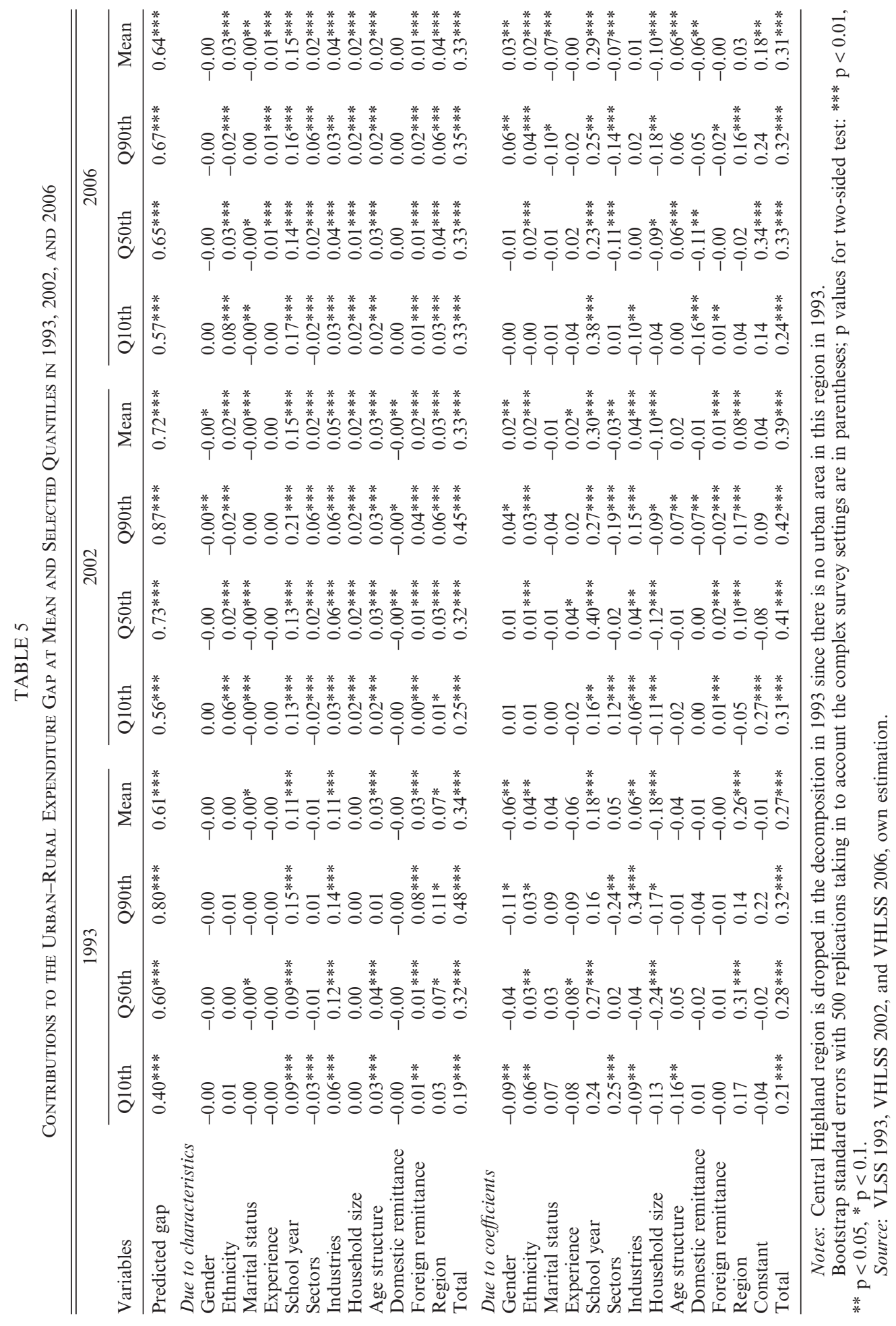


return to education in the urban sector compared to the rural ones together explain 48 percent ( 0.29 log points) of the overall urban-rural expenditure gap in 1993, 63 percent (0.45 log points) of the overall urban-rural expenditure gap in 2002, and up to 69 percent (0.44 log points) of the overall urban-rural expenditure gap in 2006. The average urban-rural gap in return to education at the mean increases remarkably in the initial period of reform, 1993 to 2002. Along the distribution, while the gap is stable in the lower part of the distribution, it increases substantially in the middle and the upper parts of the distribution. The evolution of the urban-rural gap in return to education in the middle and the upper parts of the distribution explains considerably the widening the overall urban-rural expenditure gap between 1993 and 2002. In the latter observed transition period, 2002 to 2006, return to education for the poor increases remarkably nationwide but the rate of increase is higher in the urban sector. As a result, in this latter period, the urban-rural gap in return to education in the lower parts of the expenditure distribution increases. However, in the middle and upper parts of the expenditure distribution, the urban-rural gap in return to education declines.

The second important contributing factor is the urban-rural difference in industrial structure. Over time, as Vietnam became more developed and the rural areas became more industrialized, the contribution of the urban-rural industrial structure differences to the overall urban-rural expenditure gap declines. The contribution reduces from 10 percent ( 0.06 log points) in 1993 to 2 percent $(0.01$ $\log$ points) in 2006. The urban-rural differences in return by industries also decline significantly over the period and its contribution to the overall urban-rural expenditure gap is no longer significant in 2006.

We evaluate separately the role of foreign and domestic remittance receipt in contributing to the overall urban-rural expenditure gap. Together with the country's massive rural-urban migration, receipt of domestic remittances plays an increasingly important role in reducing the urban-rural expenditure gap. By 2006, domestic remittance receipt is associated with a significant reduction in the average urban-rural expenditure gap of 10 percent ( $0.06 \mathrm{log}$ points). Along the expenditure distribution, the role of domestic remittance receipt in narrowing the urban-rural gap is highest at the lower end. While domestic remittance significantly narrows the urban-rural expenditure gap, foreign remittance slightly widens the gap. Specifically, foreign remittance increases the average urban-rural gap by 5 percent in 1993, 4 percent in 2002, and 2 percent in 2006.

Other factors contributing positively to the overall urban-rural gap include the inter-group differences by ethnicity, household age structure, and region. A significant part of the unexplained component lies in the intercept, which is the urban-rural difference in other factors not captured in the model. ${ }^{13}$ These are likely to include infrastructure, geographic conditions and the like, and to favor the urban sector in the latter year of the observed period.

\footnotetext{
${ }^{13}$ The sample stratifications for 2002 and 2006 allow us to use regional dummies at the provincial level, which was not possible for the first two VLSSs. Our estimates using these regional dummies at the provincial level show that urban-rural differences in the constants still account for a significant part of the unexplained component. These estimates are available from the authors on request.
} 


\section{Conclusions and Discussions}

In this paper, we investigate urban-rural living standard inequality in Vietnam during the 1993 to 2006 period. Our study contributes to the economic literature in three important ways. First, the new method of unconditional quantile regression (Firpo et al., 2009) is applied to examine the determinants of expenditure along the distribution. Second, the Oaxaca-Blinder type decomposition for the unconditional quantile regression method is employed to isolate the factors that contribute to the urban-rural expenditure gap. Third, our study covers a 13-year period of the country's accelerated transition with restructuring, marketization, and opening up the economy, which is longer than previous studies on urban-rural living standard inequality in Vietnam covering only five years between 1993 and 1998.

We find that, while the living standard of Vietnamese people improves, there is substantial urban-rural inequality. Urban-rural inequality increased significantly in the initial period of reform, peaked in 2002, and then declined. This is different to China, a comparable country in many aspects. China has experienced continuously increasing urban-rural inequality since its reform in 1978 (Asian Development Bank, 2007). Recent trends in Vietnam from 2002 to 2006 show signs of reducing overall inequality as well as urban-rural inequality. The results confirm assessments of the World Bank (2008), Glewwe and Dang (2011), and Arndt et al. (2012), as well as many other international observers and researchers, that the Vietnam's economic growth in recent years is broad-based.

An important explanation for the recent evolution of Vietnamese urban-rural inequality relates to migration. ${ }^{14}$ In the centrally planned period until the early 1990s (when our analysis began), the Vietnamese government tightly controlled migration flows (Van de Walle and Gunewardena, 2001). Local government in the large urban centers set tough barriers for rural people to migrate to cities; for example, in order to migrate, a migrant must have a house as well as a permanent job in an urban area. However, in the late 1990s, regulations governing geographic movement became less rigorous, and the registration procedure for people relocating was progressively relaxed. During the period of our study, Vietnam's law on residence was amended twice, first in 2001 and then in $2006 .{ }^{15}$ Nowadays, rural migrants can access urban education and urban health insurance, and purchase an urban house if they can afford it. Consistent with the massive rural-urban migration, we observe a large increase in the proportion of rural households receiving domestic remittance. In the latter years of our observation period, receipt of domestic remittances plays a significant role in improving rural households' expenditure, and the impact is biggest for the rural poor. By improving rural households'

\footnotetext{
${ }^{14}$ In our observed sample, there are 151 households who were registered in a rural area in 2002 and moved to an urban area by 2004, and in 2004 there are 147 households registered in rural areas who moved to an urban area by 2006. Our estimation and decomposition results remain almost the same when we exclude these households from our observed sample. So the expansion of urban areas is not an important explanation for the reduction of the urban-rural gap.

${ }^{15}$ According to Vietnam's Law on Residence issued in the Constitution in 1992 and amended two times in 2001 and 2006, Vietnamese people have the right to freedom of residence in the territory of Vietnam (The National Assembly, 1992, 2001, 2006).
} 
expenditure, domestic remittance significantly shortens the urban-rural expenditure gap.

Our decomposition results suggest a number of factors contributing positively to the high urban-rural expenditure gap. These include the inter-group differences in education, labor market activity, ethnicity, household age structure, geographic location, and their related returns. Adjusting the average characteristics of rural households to those of urban households will shorten about 50 percent of the urban-rural expenditure gap.

Among the contributing factors, education plays the most important role. The evolution of the urban-rural differentials in return to education also plays an important role in explaining the changes in the urban-rural inequality. That is, in the initial period of reform, 1993 to 2002, the urban-rural differentials in return to education increase significantly. The urban middle and upper class benefited greatly from a large increase in return to their education. However, in the latter time of our observed period, in both urban and rural sectors, return to education is highest for the poor, suggesting that policies helping the rural poor improve their education will significantly reduce inequality.

During the studied period, as the country becomes more developed and industrialized, the urban-rural differential in industrial structure declines and this reduction shortens the urban-rural expenditure gap. However, despite the fact that there has been a significant labor transformation from the rural traditional agricultural sector to the newly developed urban industrial sector over the country's development process, agriculture is still the industry with the lowest return in comparison with the service and manufacturing industry. In particular, we have seen little improvement in return for poor households working in agriculture. Therefore, we would argue that support given to poor rural households to increase their agricultural productivity is needed to reduce poverty as well as urban-rural inequality.

\section{REFERENCES}

Arndt, C., A. Garcia, F. Tarp, and J. Thurlow, "Poverty Reduction and Economic Structure: Comparative Path Analysis for Mozambique and Vietnam," Review of Income and Wealth, 58, 742-63, 2012.

Asian Development Bank, "Inequality in Asia," in Asian Development Bank (ed.), Key Indicators 2007, ADB Publishing House, Manila, Part I, 4-95, 2007.

Biewen, M., "Bootstrap Inference for Inequality, Mobility and Poverty Measurement," Journal of Econometrics, 108, 317-42, 2002.

Blinder, A. S., "Wage Discrimination: Reduced Form and Structural Estimates," Journal of Human Resources, 8, 436-55, 1973.

Chi, W. and B. Li, "Glass Ceiling or Sticky Floor? Examining the Gender Earnings Differential across the Earnings Distribution in Urban China, 1987-2004," Journal of Comparative Economics, 36, 243-63, 2008.

Fesselmeyer, E. and K. T. Le, "Urban-Biased Policies and the Increasing Rural-Urban Expenditure Gap in Vietnam in the 1990s," Asian Economic Journal, 24, 161-78, 2010.

Firpo, S., N. M. Fortin, and T. Lemieux, "Unconditional Quantile Regressions," Econometrica, 77, 953-73, 2009.

Fortin, N. M., "The Gender Wage Gap among Young Adults in the United States: The Importance of Money Versus People," Journal of Human Resources, 43, 886-920, 2008.

Fortin, N. M., T. Lemieux, and S. Firpo, "Decomposition Methods in Economics," in O. Ashenfelter, R. Layard, and D. Card (eds), Handbook of Labor Economics, Elsevier, Amsterdam, Part A, 1-102, 2011. 
General Statistics Office of Vietnam, Vietnam Household Living Standard Surveys, 2002 and 2004: Basic Information, Hanoi, 2006.

- Statistical Handbook of Vietnam 2008, Statistical Publishing House, Hanoi, 2009.

Glewwe, P. and H.-A. H. Dang, "Was Vietnam's Economic Growth in the 1990s Pro-Poor? An Analysis of Panel Data from Vietnam," Economic Development and Cultural Change, 59, 583-608, 2011.

Glewwe, P. P., M. M. Gragnolati, and H. H. Zaman, "Who Gained from Vietnam's Boom in the 1990s?" Economic Development and Cultural Change, 50, 773-92, 2002.

Grün, C. and S. Klasen, "Growth, Income Distribution and Well-Being in Transition Countries," Economics of Transition, 9, 359-94, 2001.

Hampel, F. R., "The Influence Curve and Its Role in Robust Estimation," Journal of the American Statistical Association, 69, 383-93, 1974.

Jann, B., "The Blinder-Oaxaca Decomposition for Linear Regression Models," The Stata Journal, 8, 453-79, 2008.

Kassenböhmer, S. and M. Sinning, "Distributional Changes in the Gender Wage Gap," Working Paper in Economics and Econometrics No. 532, Research School of Economics, The Australian National University, 2010.

Koenker, R. and G. Bassett, "Regression Quantiles," Econometrica, 46, 33-46, 1978.

McCaig, B., D. Benjamin, and L. Brandt, "The Evolution of Income Inequality in Vietnam, 1993 2006," Mimeo, The Australian National University, 2009.

Mundle, S. and B. V. Arkadie, "The Rural-Urban Transition in Vietnam: Some Selected Issues," EDRC Occasional Papers, Asian Development Bank, 1997.

Nguyen, B. T., J. W. Albrecht, S. B. Vroman, and M. D. Westbrook, "A Quantile Regression Decomposition of Urban-Rural Inequality in Vietnam," Journal of Development Economics, 83, 466-90, 2007.

Oaxaca, R., "Male-Female Wage Differentials in Urban Labor Markets," International Economic Review, 14, 693-709, 1973.

Phan, D. and I. Coxhead, "Inter-Provincial Migration and Inequality During Vietnam's Transition," Journal of Development Economics, 91, 100-12, 2010.

Pincus, J. and J. Sender, "Quantifying Poverty in Viet Nam: Who Counts?" Journal of Vietnamese Studies, 3, 108-50, 2008.

Powell, D., "Unconditional Quantile Regression for Exogenous or Endogenous Treatment Variables," RAND Working Paper, No. 824, 2011.

Rama, M., Moving to Middle Income Status: Donors and Vietnam Beyond 2010, The World Bank, Hanoi, 2008.

-, "Poverty Reduction and Social Protection in Vietnam," Paper Presented at The Second Economic Workshop on Vietnam, Research School of Economics, The Australian National University, 2010.

Ravallion, M. and Q. Wodon, "Poor Areas, or Only Poor People?” Journal of Regional Science, 39, 689-711, 1999.

Sakellariou, C., "Unconditional Quantile Regressions, Wage Growth and Inequality in the Philippines, 2001-2006: The Contribution of Covariates," Applied Economics, 44, 3815-30, 2011.

Sicular, T., Y. Ximing, B. Gustafsson, and L. Shi, "The Urban-Rural Income Gap and Inequality in China," Review of Income and Wealth, 53, 93-126, 2007.

The National Assembly, "The Socialist Republic of Vietnam's Constitution," Ministry of Justice, Hanoi, 1992.

- "Labour Code of The Socialist Republic of Vietnam," Ministry of Justice, Hanoi, 1994.

, "The Socialist Republic of Vietnam's Law on Residence, Pursuant to the 1992 Constitution Amended 2001," Ministry of Justice, Hanoi, 2001.

- "The Socialist Republic of Vietnam's Law on Residence, Pursuant to the 1992 Constitution Which was Amended and Supplemented under Resolution No. 51/2001/Qh10, Amended in 2006," Ministry of Justice, Hanoi, 2006.

United Nations, "World Urbanization Prospects: The 2007 Revision Population Data Base," United Nations Population Division, New York, 2008a.

_ York, 2008b.

Van de Walle, D. and D. Gunewardena, "Sources of Ethnic Inequality in Viet Nam," Journal of Development Economics, 65, 177-207, 2001.

Vietnamese Academy of Social Science, "Poverty Update Report 2006: Poverty and Poverty Reduction in Vietnam 1993-2004," Hanoi, 2007. 
World Bank, "Meaning of Variables in the Household Expenditure File of The Vietnam Living Standards Survey 1992-93," Poverty and Human Resources Division, 1998a.

, "The Data Set of Vietnam Living Standards Survey 1992-93," Poverty and Human Resources Division, 1998b.

, "Vietnam Living Standards Survey 1997-98: Basic Information," Poverty and Human Resources Division, 2001.

— , "Urbanization Dynamics and Policy Frameworks in Developing East Asia," East Asia Infrastructure Department, 2004.

, "Vietnam Development Report 2008: Social Protection," Hanoi, 2008.

\section{SUPPORTING INFORMATION}

Additional Supporting Information may be found in the online version of this article at the publisher's web-site:

Appendix A: Distribution of Expenditure in Urban and Rural Areas, 1993-2006

Appendix B: Gini Index of Selected Countries

Appendix C1: Theil Decomposition by the Contribution of Within and Between Groups, 1993-2006

Appendix C2: Theil Decomposition by the Contribution of Within and Between Groups, 1993-2006

Appendix C3: Theil Decomposition by the Contribution of Within and Between Groups, 1993-2006

Appendix D: Share of Expenditure Enjoyed by Quintiles (\%), 1993-2006

Appendix E: Variable Description and Summary Statistics, 1993-2006

Appendix F: Selected Estimating Coefficients Along the Distribution in Urban-Rural Areas, $1993 \& 2006$ 